\title{
REPENSANT LA GOVERNANÇA \\ DE LA CREATIVITAT A LES CIUTATS
}

\section{Montserrat Pareja-Eastaway \\ GRC Creativitat, innovació i transformació urbana - Universitat de Barcelona}

RESUM: El context internacional afecta directament les estratègies urbanes de competitivitat: les polítiques tradicionals basades en la millora de les infraestructures i el conjunt de tangibles a la ciutat, s'han transformat en accions d'índole diversa d'estímul al voltant de la creativitat i el coneixement. Hi ha consens al voltant del retrocés de les polítiques top-down o de dalt a baix, en les agendes locals mentre que, de manera creixent, s'incorporen noves articulacions d'acció publicoprivada, on les iniciatives bottom-up o de baix a dalt, assumeixen un protagonisme rellevant. Simultàniament, es produeix l'emergència de nous actors en el procés d'intervenció i millora a les ciutats. Aquest article presenta aquesta transformació i procés al voltant de la creativitat com a eix vertebrador de la nova competitivitat urbana. Però, podem governar la creativitat? Podem fer d'una ciutat, un espai harmònicament creatiu? Consens i diàleg són pedres de toc de la nova governança: del reconeixement de les forces existents al territori i del diagnòstic compartit per tots els actors involucrats sorgeixen arguments per a una ciutat no només competitiva sinó també representativa del teixit socioeconòmic existent.

Paraules clau: creativitat, ciutat, competitivitat urbana, governança.

RESUMEN: El contexto internacional afecta directamente a las estrategias urbanas de competitividad: las políticas tradicionales basadas en la mejora de las infraestructuras y el conjunto de tangibles en la ciudad se han transformado en acciones de índole diversa de estímulo alrededor de la creatividad 
y el conocimiento. Existe consenso alrededor del retroceso de las políticas top-down, o de arriba abajo, en las agendas locales mientras que, de manera creciente, se incorporan nuevas articulaciones de acción público-privada, donde las iniciativas bottom-up, o de abajo arriba, asumen un protagonismo relevante. Simultáneamente se produce la emergencia de nuevos actores en el proceso de intervención y mejora en las ciudades. Este artículo presenta esta transformación y proceso alrededor de la creatividad como eje vertebrador de la nueva competitividad urbana. Sin embargo, ¿podemos gobernar la creatividad? ¿Podemos hacer de una ciudad un espacio armónicamente creativo? Consenso y diálogo son piedras de toque de la nueva gobernanza: del reconocimiento de las fuerzas existentes en el territorio y de la diagnosis compartida por todos los actores involucrados surgen argumentos para una ciudad no sólo competitiva sino también representativa del tejido socioeconómico existente.

Palabras clave: creatividad, ciudad, competitividad urbana, gobernanza.

ABSTRACT: The international context directly affects urban strategies for competitiveness: traditional policies based on the improvement of infrastructure and the tangibles in the city have become actions of various types for stimulation based around creativity and knowledge. There is consensus on the decline of top-down policies in local agendas, while new joint public-private actions, in which bottom-up initiatives play a crucial role, are increasingly being incorporated. New actors in the process of intervention and improvement in cities are simultaneously emerging. This article presents this transformation and process based around creativity as the backbone of the new urban competitiveness. But can we govern creativity? Can we make a city a harmoniously creative space? Consensus and dialogue are touchstones of the new governance: arguments for a city that is not only competitive but also representative of the existing socio-economic fabric arise from recognition of the forces existing in the territory and of the diagnosis shared by all the stakeholders.

KEYWORDS: creativity, city, urban competitiveness, governance. 


\section{Ciutat, governança i creativitat}

$\mathrm{T}_{\mathrm{i} \text { (a) }}$ ant les ciutats com les regions reflecteixen els canvis econòmics en curs i evidencien les consegüents transformacions socials. Des de la darrera onada de globalització a finals de segle xx, el territori s'ha adaptat a les noves necessitats emergents dels nous i internacionalitzats sistemes de producció. La dicotomia entre el local i el global ha estat l'eix de molts debats acadèmics que fan no només compatible sinó complementari el que aparentment sembla contradictori o fins i tot, oposat (Sassen, 1991; Borja i Castells, 1997; Marcuse i van Kempen, 2000; Kazepov, 2004); és d'especial interès la manera com les ciutats i les regions articulen el desafiament econòmic global, amb les seves potencialitats i d'acord amb les seves necessitats, on particularment, el paper de les polítiques locals per a aconseguir l'èxit són un element central en la dicussió.

La ciutat com a ens dinàmic es defineix a cada moment per l'espai construït, la cultura local i l'exercici de la governança pels agents que hi participen. La transferència de poder per a governar el territori des de les instàncies tradicionals (i. e. els governs centrals o subcentrals) a altres actors implicats en el comandament de la ciutat (i. e. societat civil, el mercat o les xarxes, entre altres) ha assolit canvis profunds en les darreres dècades (Rhodes, 1997). La governança o govern compartit ha requerit nous esquemes de diàleg i de finançament així com noves figures i mecanismes articuladors en el disseny, implementació i avaluació de les intervencions. Així, els contextos urbans han canviat i també ho han fet els mecanismes de governança. Tal com Pareja-Eastaway i Pradel i Miquel (2010) assenyalen, les dificultats creixents en el govern de les ciutats s'expliquen no tan sols per la complexitat de la vida social, sinó també per les noves interdependències i relacions entre empreses. En aquest sentit, factors socials, econòmics i polítics a l'esfera local determinaran, juntament amb les estratègies nacionals, la capacitat de la ciutat per a afrontar els reptes de la competitivitat global.

El desenvolupament de la creativitat i el coneixement per a l'èxit econòmic d'un territori semblen ser pedres angulars en la construcció d'una ciutat competitiva. En particular, el consens dels actors involucrats, l'articulació de la governança $\mathrm{i}$ el benefici que representa el reconeixement de la path 
dependency en el decurs de la trajectòria de ciutat, es posa de manifest en el bon funcionament de la ciutat. L'economia creativa i del coneixement són els nous eixos de la competitivitat de les ciutats que determinen la seva posició en la jerarquia urbana (Bontje et al., 2011). En pocs anys, els agents socials han transformat la seva relació amb les activitats econòmiques i el comportament d'una manera radical: l'activitat econòmica a les ciutats s'ha desplaçat del model postfordista en què la competència en preus i costos determina la localització de l'activitat econòmica a un nou patró de la ubicació en què la capacitat de mobilització de recursos com ara el talent o la capacitat de crear, són clau per a assegurar un futur estable i sostenible (Pareja-Eastaway i Piqué, 2010). En aquest context, i tenint en compte les relativament recents millores en les TIC, la societat ha esdevingut altament mòbil i dinàmica, no només físicament sinó també virtualment: al segle XXI, les noves formes de comunicació i relació estan canviant el significat i contingut de la dimensió local. L'agenda digital ha canviat la vida quotidiana i la participació en les xarxes socials i professionals de la ciutadania sense que hi hagi necessàriament un component territorial. No obstant això, tal com manifesten Scott (2008) i Castells (2010), en la nova onada del capitalisme, les ciutats s'han convertit en el motor de l'economia mundial.

Així doncs, els mecanismes per a treure activitat econòmica o el talent, han estat revisats i actualitzats davant els canvis soferts en les relacions tant econòmiques com socials per la revolució digital i les noves formes de producció. Mentre que certs enfocaments consideren l'atractiu de la ciutat en termes de tolerància, la qualitat de vida i l'ambient, com els aspectes clau per a l'èxit i l'acollida del talent i la creativitat (Florida, 2002), altres reforcen la idea que considera que les grans xarxes globals de producció són determinants per a la concentració de les activitats i de la població en les regions metropolitanes (Castells, 2010). En resum, les variables estàtiques vinculades als atributs locals de la ciutat s'enfronten a fluxos de comunicació i transmissió de coneixements a escala mundial. Els responsables polítics i els actors rellevants a la majoria de ciutats estan buscant, aïlladament o conjuntament, la combinació adequada d'intervencions: millors infraestructures per atreure les empreses, ambients atractius per a atreure talent, generació de macroprojectes i esdeveniments mundials per augmentar la visibilitat, entre d'altres. La diversitat de les ciutats és enorme en termes de dimensió, especialització 
econòmica i trajectòria: difícilment podrien seguir la mateixa estratègia per convertir-se en ciutats reeixides per atreure l'activitat econòmica (Musterd i Gritsai, 2013).

Davant la confluència entre la ciutat competitiva i el món global i l'aparició de la creativitat i el coneixement com a eixos fonamentals en la creació de valor, hom es demana quina és l'articulació de la governança a la ciutat que permet crear aquest espai fèrtil i productiu que determini tant l'augment de l'activitat econòmica d'alt valor afegit i l'ocupació com la millora en la qualitat de vida dels ciutadans. La ciutat multi-layered o conformada per diferents estrats o nivells, tant en termes de caracterització de població com ara grups ètnics o gènere (Thompson, 2000) com d'acord a diferents capes de govern o governança (Jansen-Verbeke i Govers, 2010) o segons els diferents substrats incorporats al llarg del procés històric (Musterd i Murie, 2010), apareix com una nova articulació de ciutat, polifacètica i complexa, altament dinàmica $\mathrm{i}$ canviant. Cohendet et al. (2010) aposten per una anatomia de ciutat creativa on tres capes d'actors i/o comunitats (underground, middleground i upperground) interaccionen per a dotar-se dels inputs necessaris per a fer emergir, produir i aplicar la creativitat, sent de màxima rellevància els espais que la ciutat ofereix per a tal interacció. En definitiva, la creixent complexitat de la ciutat fa que l'articulació d'aquestes capes sigui flexible i adaptable per tal de maximitzar la necessària interrelació entre elles i, particularment, per a promoure una ciutat diversa, creativa, multicultural i rica. La bona governança consisteix precisament en això.

En resum, els canvis polítics, econòmics i socials transformen el paper de la ciutat en el món contemporani i fan de la creativitat un valor en alça: potenciar una economia i una societat creativa requereix noves perspectives d'anàlisi dels mecanismes de governança, atesa la complexitat de les interrelacions entre qui participa i vol ser representat a la ciutat. En particular, aquest article presta atenció a les trajectòries, les xarxes i la densitat institucional en la governança de la creativitat. 


\section{Governança de la creativitat: trajectòries, xarxes i densitat institucional}

La substitució en els darrers anys del model fordista per models més flexibles de producció ha comportat el declivi d'algunes activitats econòmiques i l'ascensió d'altres, en particular, aquelles que incorporen grans dotacions de capital humà (Bontje et al., 2011). Simultàniament, la globalització dels mercats i l'adveniment de les noves tecnologies se sumen com a factors transformadors de la ciutat i del seu model de competitivitat. Tal com s'ha mencionat anteriorment, el sorgiment de la «nova economia», on els sectors creatius i del coneixement són eixos fonamentals, ha determinat noves fórmules perquè les ciutats competeixin, atorgant un pes específic i diferenciador a certs factors productius, això és: el talent la innovació i la creativitat, els quals esdevenen fonamentals en el desenvolupament i l'èxit de les ciutats creatives i, en particular, de la «classe creativa» (Florida, 2002).

En aquest context, les ciutats tenen un paper cabdal on el coneixement i el capital humà són factors essencials. La ciutat es converteix en un pol d'atracció d'activitat creativa, de talent i de valor afegit. Les indústries creatives emergeixen com a elements clau en el desenvolupament econòmic urbà i el canvi d'enfocament i la voluntat de potenciar les activitats creatives com a motor econòmic s'expandeix també a la resta de la dimensió urbana ( $\mathrm{Pa}$ reja-Eastaway, 2011). Les indústries culturals sorgeixen com el hard core de l'activitat creativa, però també una gran part de les indústries creatives es correlacionen amb activitats intensives en coneixement, sent sovint, creativitat i coneixement difícils de desvincular.

Si acceptem que les ciutats es poden caracteritzar d'acord amb les seves pròpies trajectòries econòmiques, els agents principals que conformen el seu teixit social i econòmic $\mathrm{i}$ les polítiques que desenvolupen (Musterd i Gritsai, 2009), la seva capacitat d'adaptar-se a les noves exigències de l'economia mundial dependrà de com juguin aquests elements a favor de la implicació de la ciutat en la nova configuració d'una jerarquia urbana mundial. El paper que la governança assumeix en aquest context és determinant per al disseny d'un discurs comú i compartit per tots els actors; amb un llistat de prioritats clar i consensuat. 
Més enllà de receptes que governin la creativitat, es tracta de promoure un entorn que potenciï i estimuli els trencaments disruptius i la seva possible transferència a la innovació. La ciutat requereix polítiques fetes a mida, no de receptes estàndard (Musterd i Kóvacs, 2013). A continuació se subratllen tres elements determinants que cal tenir en compte en el disseny d'una governança de ciutat ad hoc: les trajectòries, les xarxes i la densitat institucional.

\section{La importància de les trajectòries}

La localització de l'activitat econòmica general segueix alguns incentius, com ara beneficiar-se de les externalitats creades entre les empreses i les sinergies entre els diferents processos productius. No obstant això, l'impacte global sobre el territori depèn en gran mesura de la tecnologia disponible, l'estructura del mercat i dels patrons anteriors d'industrialització. Els beneficis de l'atracció de certes activitats econòmiques a la ciutat depenen essencialment de com el territori s'ha tingut en compte en aquest procés i com aquest es combina amb l'arribada d'aquestes activitats (Scott, 2008). D'altra banda, els vincles econòmics establerts entre les empreses van de la mà amb la proliferació d'una àmplia gamma d'interaccions socials que, encara que basada en el teixit econòmic, permet avançar en l'establiment de complicitats personals i professionals, la qual cosa afavoreix la transmissió dels efectes secundaris d'aquesta xarxa complexa al món real. Això és particularment cert en els sectors creatius i de coneixement que tenen en compte el capital humà i el talent com un input decisiu per treure el màxim profit de les noves oportunitats associades a la nova economia.

Els processos econòmics, culturals i polítics creats i desenvolupats a les regions determinen el seu posicionament històric, la seva transformació industrial, la caracterització geopolítica del territori i l'impacte de les polítiques públiques (Kóvacs et al., 2007). D’acord amb això, dues magnituds són rellevants en l'estudi de la ciutat competitiva d'avui: l'econòmica i la social. Més enllà d'aspectes al voltant dels indicadors econòmics i la seva magnitud, l'abast de l'estructura social i d'organització del territori indica una singularitat associada a cada territori. Aquesta unicitat s'explica a través del paper que representen certs factors de promoció de la ciutat, com ara la composició diversa de la societat, les seves tradicions polítiques i el conjunt d'actors i 
polítiques que promouen i estimulen la creativitat i la innovació en l'àmbit territorial (Pareja-Eastaway i Piqué, 2010).

\section{La rellevància de les xarxes}

La dependència històrica no es limita a l'evolució del teixit productiu o al grau de participació en les noves formes de competència. Un dels aspectes fonamentals en aquesta anàlisi de l'actualitat de les ciutats és la seva capacitat per a crear un entorn favorable a la generació d'idees, capacitats i talent, l'anomenada «ecologia de la innovació» (Munroe i Westwing, 2009). Sens dubte, és un procés històric que aferma la ciutat com un punt de referència en la producció de coneixement o habilitats. No obstant això, aquesta capacitat de la ciutat adquireix una nova magnitud en la configuració global actual. Entre d'altres, el paper cada vegada més important de la connectivitat i les xarxes en l'economia del coneixement crea nous reptes per al territori: la capacitat de crear ponts entre el local i el global es torna rellevant més enllà de les fronteres pròpies de la ciutat. Per tant, les infraestructures de connectivitat en totes les formes possibles, tots els modes de transport, xarxes de telecomunicacions i sistemes d'informació són, entre d'altres, aspectes clau per millorar la capacitat de la ciutat per pertànyer a l'arquitectura global de les xarxes.

El debat acadèmic en curs en relació amb les ciutats creatives actualment està prestant atenció a la rellevància de les xarxes, tant de caràcter internacional entre les ciutats i les empreses, com en la dimensió local, establint forts lligams entre els actors rellevants de l'economia del coneixement. En el procés de la globalització, les connexions entre les diferents parts de l'augment de territori fomenten l'intercanvi de coneixements i habilitats. De tots els grups d'interès que porten a terme aquest procés, els que tenen la més alta qualificació i aquells que són especialistes i mostren el seu profund coneixement de certes habilitats es converteixen en el focus de les ciutats. Les teories vinculades amb la generació de clústers d'especialització relacionats amb xarxes internacionals estan directament associades a dos elements entesos com a causes històriques locals que determinen la proliferació de certes activitats: d'una banda, la percepció que apunta a la història local en tots els seus aspectes, ja siguin econòmics, socials, institucionals o culturals i, d'una altra, els actors que hi participen. 
En la mateixa línia, la creació d'un entorn innovador que permet tant l'intercanvi d'experiències al llarg de diferents etapes de la cadena de valor com el sorgiment de noves idees, és part de la majoria de les agendes polítiques i un dels objectius estratègics de la majoria de les ciutats i regions de tot el món. L'ús de la seva pròpia especialització no només ofereix avantatges comparatius per a la ciutat, sinó també afavorir la creació de nodes urbans d'un conjunt variat dels fluxos d'informació i experiències que ofereixen una ciutat de múltiples capes on la convergència dels diferents nivells de les xarxes ajusta el seu valor afegit a l'esfera urbana global.

\section{Governança i densitat institucional}

En aquest context, una característica addicional que s'ha de tenir en compte és la capacitat proporcionada pel mecanisme de governança, arrelat per definició en el substrat social i institucional de la ciutat, per a crear vincles i oportunitats per atreure i estimular la creació de negocis i l'emergència del talent. No obstant això, les estratègies adoptades per les entitats públiques $\mathrm{i}$ privades que tracten d'estimular la creativitat i el coneixement poden diferir considerablement d'acord amb alguns elements específics capaços de canviar el resultat de les mesures adoptades: el calendari en l'adopció d'iniciatives, la participació de les parts interessades i els consensos assolits, són algunes qüestions que cal considerar en l'anàlisi de la contribució de la governança per a l'èxit de les mesures adoptades (Pareja-Eastaway i Pradel, 2010).

L'evidència mostra que les ciutats, a través de les seves polítiques públiques, es reinventen contínuament per a adaptar-se a les exigències de qualsevol època, en particular a les de l'economia creativa i del coneixement (Crossa et al., 2010). No obstant això, l'èxit o el fracàs en l'adopció de mesures específiques que vagin més enllà de l'eficiència de l'acció depèn de la capacitat del territori de beneficiar-se de l'herència històrica i de les mateixes particularitats d'allà on s'implementa la política. La revolució provocada per l'economia global és anàloga a un canvi en profunditat de les estructures de govern. Aconseguir un equilibri entre les iniciatives top-down i els que vénen de la societat civil tot generant processos d'innovació social, és un dels reptes de futur més importants per a molts organismes locals (Manito i Pareja-Eastaway, 2010). 


\section{Polítiques públiques i estructures de governança}

La creixent importància de la cultura i la creativitat i de les empreses intensives en coneixement a les ciutats no és només el resultat de la confluència a l'atzar de diversos determinants favorables, sinó un esforç decidit per fomentar l'economia urbana sobre la base de la creativitat i el coneixement que es beneficien de l'estructura existent i la tradició industrial. Diverses investigacions (ACRE, CREAURBS, INNOVA) ${ }^{1}$ subratllen els elements que cal considerar en la definició d'estratègies, polítiques i projectes que adrecin l'estímul de la creativitat i el coneixement al territori. Entre d'altres:

1. Arrelament dels actors. La connexió de persones a la zona (social, econòmica, educativa, etc.) esdevé una variable fonamental per explicar per què certs sectors creatius emergeixen amb força. L'esforç realitzat, per exemple, per les universitats i centres de recerca a les ciutats per tal d'atreure el talent a través de bons programes d'educació superior, ha d'anar necessàriament vinculat a la creació de llocs de treball ben qualificats al territori. Aquest esforç requereix la seva participació en la planificació estratègica del territori tot contribuint a l'establiment d'objectius coherents amb els programes nacionals, regionals i locals d'educació.

2. Planificació estratègica i consens de prioritats. La planificació estratègica és un instrument clau per reduir al mínim el malbaratament d'esforços en la promoció del desenvolupament de la ciutat. Els primers passos en la planificació estratègica desenvolupats en la dècada de 1980, que cobreixen tot el desenvolupament estratègic de la ciutat, es troben actualment acompanyats per la proliferació de molts programes amb una perspectiva estratègica en una variada gamma d'assumptes com ara el turisme, l'ocupació o la cultura.

1. ACRE (Projecte Finançat pel 6è Programa marc de la UE, 2007-2010): Accommodating Creative Knowledge. www.acre.socsci.uva.nl; CREAURBS (Projecte d'Investigació Fonamental no orientada, Ministerio de Economía y Competitividad. España 20092012): Creatividad y conocimiento: bases para una nueva competividad urbana. www. crit.ub.edu/creaurbs. INNOVA (Projecte d'Investigació Fonamental no orientada, Ministerio de Economía y Competitividad. España. 2013-2015): Innovación, creatividad y cultura: Definiendo las bases de un nuevo modelo socio-económico para una España post-crisis. www.crit.ub.edu/innova 
3. Definició de la imatge de ciutat. Hi ha acord sobre la importància de la imatge de ciutat en l'atracció de talent i empreses que basen la seva activitat en la creativitat i el coneixement. No obstant això, la necessitat d'una constant reformulació dels continguts associats a aquesta imatge és també un element que cal tenir en compte. La imatge de la ciutat atreu turisme i negocis però també reivindica el sentit de pertinença ciutadana dels que hi viuen. La confrontació d'aquestes dues visions i la cerca de coherència entre ambdues requereix diàleg i reconeixement de les diferents imatges que suscita i d'aquella amb què la societat s'identifica amb la ciutat.

4. Accountability o representativitat. Probablement, un dels reptes més importants per a la governança sigui ser representativa dels interessos de tots els actors implicats. En qüestió de creativitat i cultura, la direcció del projecte de futur de la ciutat hauria d'anar encaminada a recollir les diferents sensibilitats que existeixen a la ciutat: més enllà de discursos unidireccionals i fronteres insalvables, la governança compartida requereix representants responsables que simbolitzin visions, sovint alternatives, però necessàriament dialogades del futur.

5. Polítiques directes. Les polítiques directes orientades a promoure la cultura, la creativitat i les activitats intensives en coneixement no es poden aïllar d'altres polítiques que, encara que de manera indirecta, també contribueixen a la competitivitat de la ciutat. Per exemple, és indubtable que la millora dels factors hard, com ara autopistes o aeroports, atreu les empreses i, a la vegada, mà d'obra qualificada. Sovint a l'esfera local convergeixen diferents nivells de govern. Per tant, si bé l'estratègia del govern local és sens dubte fonamental per al disseny i implementació de polítiques de foment de la creativitat i el coneixement, el govern nacional sorgeix amb un paper clau en la decisió de les mesures i polítiques que acompanyen les adoptades pel govern local. En molts casos, aquest fet ha contribuït a la proliferació d'acords entre diferents municipis (tot i el seu color polític diferent).

L'esforç conjunt i la cooperació demostren ser econòmicament més rendibles que la competència. El paper de facilitador entre els actors s'assumeix 
clarament per l'administració pública, però les responsabilitats es comparteixen entre aquells que participen en el disseny de l'estratègia urbana de futur. L'aportació de recursos, no necessàriament monetaris, legitima l'acció dialogada en la ciutat.

\section{Reflexions finals}

La majoria de reflexions al voltant de les activitats creatives i del coneixement al territori constaten la cabdal rellevància que assoleixen com a motor de creixement, innovació i competitivitat.

Hi ha aspectes sobre els quals no es pot actuar directament, com ara la posició històrica de la ciutat o la ubicació geogràfica. Tot això està relacionat amb la trajectòria històrica de la ciutat (path dependency), però també amb la idea d'arrelament com a concepte determinant per a diferents actors. Per contra, els anomenats 'factors contemporanis', com ara la millora d'infraestructures o l'existència d'una bona qualitat de vida, són accions que romanen en el si de l'acció pública política. L'impacte dels lligams personals, les relacions locals i les afiliacions a diferents tipus d'organitzacions s'han convertit en elements determinants per a les ciutats.

La necessitat de reforçar el teixit industrial creatiu no tan sols passa per l'atorgament de més subvencions: els canvis en la governança a les ciutats permeten avui, més que mai, obrir un procés de diàleg compartit per a identificar exactament quins són els reptes que afecten el sector. Cooperar tant entre les diferents instàncies de sector públic com amb el sector privat, facilitar la connexió entre diferents realitats (culturals i empresarials) i compartir la diagnosi i la prioritat en l'acció són, actualment, els principals reptes davant la necessitat d'estimular els sectors creatius a la ciutat.

Els nivells de govern que se superposen a la ciutat tenen diferents papers en el metabolisme urbà, tot i que el govern local és essencialment responsable de millorar la posició de la municipalitat en la jerarquia urbana. La progressiva descentralització de les responsabilitats i les polítiques cap als nivells inferiors de govern que han tingut lloc a la majoria de països europeus ha influït decididament en la proliferació d'acords entre aquests i també en l'elaboració de programes conjunts que contribueixin a l'agrupació d'activitats. 
El bon exercici de la governabilitat és fonamental per a l'èxit en la millora de la competitivitat urbana. La naturalesa de les interaccions entre els agents que participen en la millora de la competitivitat de les ciutats pot ser explícita o tàcita: d'una banda, en molts dels acords oficials es duen a terme entre els diferents governs locals de la regió també hi poden participar els agents privats. És evident que la cooperació podria millorar la situació de tots aquests en el panorama econòmic internacional. Es detecta un canvi clar en termes de governança, des d'un enfocament de dalt a baix aïllat que té lloc en cada municipi per al conveni col·lectiu entre els diferents actors que participen en més d'un municipi. La inclusió del sector privat i la societat civil és encara més important en l'actual crisi econòmica.

La presència d'un lideratge clar en la governança d'un determinat territori és altament convenient. Molts altres actors es veuen influïts per les estratègies adoptades per l'actor-líder i configuren la seva pròpia estratègia seguint el reflex del que el líder ja ha fet. En aquest sentit, el paper del sector públic i també l'alt grau de coordinació entre els elements de la terra i la propietat i les ambicions econòmiques són cabdals per a consecució de l'èxit (Barber i Pareja-Eastaway, 2010)

La societat civil és un important component de la governança en la forma de moltes fundacions existents que promouen la creativitat i la cultura $i$ associacions reconegudes internacionalment d'actors creatius entre d'altres. La cultura cívica compartida (Mascarell, 2009) és el millor substrat per a la fertilització de la creativitat a la ciutat. Els nous creatius es defineixen com aquelles persones que accionen $\mathrm{i}$ impulsen el creixement de la nova economia tot «creant noves idees, nova tecnologia i nous continguts creatius». Segons Florida (2002), aquest grup de població, prefereix viure en espais culturalment diversos i tolerants amb una alta concentració de capital cultural i fàcil accés a les tecnologies i la connectivitat.

Seguint aquest argument, l'establiment de xarxes dintre i fora de la ciutat entre els professionals, les institucions i altres organismes és essencial en l'articulació d'una estratègia conjunta de desenvolupament econòmic. En aquest sentit, la provisió de canals per facilitar el contacte entre les empreses i també amb organitzacions públiques, és un element positiu en l'articulació de la governança. 
Governar la creativitat probablement no és, o no s'hauria d'entendre, com un repte. És més aviat el contrari: la creativitat no es governa per definició. El que sí que es presenta com un desafiament és fer convergir els discursos, els oficials i els propis dels creadors i de la ciutadania en el seu conjunt, a través del diàleg i la negociació, utilitzant la cultura com a eix transversal en la fertilització de les idees. Generar aquests espais de diàleg correspon probablement a les instàncies de govern tradicionals; aprofitar aquest context per a provocar trencaments i generar canvis consensuats en la direcció de la ciutat, és tasca de tots aquells actors que participen de la governança urbana, compartint responsabilitats i assumint els riscos pertinents.

\section{Referències}

Barber, A. i M. Pareja-Eastaway (2010): «Leadership Challenges in the Inner City: Planning for Sustainable Regeneration in Birmingham and Barcelona», Policy Studies. Vol. 31, Issue 4, Routledge, pp. 393-411.

Bontue, M.; S. Musterd; Z. Kovacs i A. Murie (2011): «Pathways toward European creative-knowledge city-regions», Urban Geography, 32(1): 80-104.

BorJa, J. i M. Castells (1997): Local y global. La gestión de las ciudades en la era de la información, Taurus, uNCHS, Madrid.

Castells, M. (2010): «Globalisation, Networking, Urbanisation: Reflections on the Information Age», Urban Studies, 2010, 47: 2737.

Cohendet, P.; D. Grandadam i L. Simon (2010): «The Anatomy of the Creative City», Industry and Innovation, 17,1: 91-111.

Crossa, V.; M. Pareja-Eastaway i A. Barber (2010): «Reinventing the city: Barcelona, Birmingham and Dublin». A Musterd, S. i A. MuRIE (2010) (eds): Making Competitive Cities, Wiley-Blackwell, Oxford.

FlORIDA, R. (2002): The rise of the creative class and how it is transforming work, leisure, community and everyday life, Basic Books, New York.

JANSEN-Verbeke, M. i R. Govers (2010): «Brussels: a multilayered capital city». A Maitland, R. i B. W. Ritchie (eds.): City Tourism: national capital perspectives (eds.), UL: CAB International, Wallingford, pp. 142-158. 
Kazepov, Y. (ed.) (2004): Cities of Europe: Changing Contexts, Local Arrangement and the Challenge to Urban Cohesion, Wiley-Blackwell, Oxford.

Kovács, Z.; A. Murie; S. Musterd; O. Gritsai i H. Pethe (2007): Comparing Paths of Creative Knowledge Regions. ACRE report 3, AMIDst, Amsterdam.

Manito, F. i M. Pareja-Eastaway (2010): «Hacia una agenda local de las industrias culturales y la creatividad». A Manito, F. (ed.): Ciudades creativas. Vol. 2. Creatividad, innovación, cultura y agenda local, Fundació Kreanta, Barcelona, pp. 281-312.

Marcuse, P. i R. van Kempen (eds.) (2000): Globalizing Cities. A New Spatial Order?, Wiley-Blackwell, Oxford.

Mascarell, F. (2009): "Ciudades creativas: industrias culturales, lugares, actores y estrategias». A Manito, F. (ed): Ciudades creativas. Vol 2. Creatividad, innovación, cultura y agenda local, Fundació Kreanta, Barcelona, pp. 27-42.

Munroe, T. i M. Westwind (2000): What Makes Silicon Valley Tick?, Nova Vista Publishing, Herentals.

Musterd, S. i O. Gritsai (2009): «Creative and knowledge cities: development paths and policies from a European perspective», Built Environment, 35(2): 173-188.

Musterd, S. i A. Murie (eds.) (2010): Making Competitive Cities, Wiley-Blackwell, Oxford.

Musterd, S. i O. Gritsai (2013): «The Creative Knowledge City in Europe: Structural Conditions and Urban Policy Strategies for Competitive Cities», European Urban and Regional Studies, 20 (3): 343-359.

Musterd, S. i Z. Kóvacs (eds.) (2013): Place Making and Policies for Competitive Cities, Wiley-Blackwell, London.

Pareja Eastaway, M. i M. Pradel (2010): «New Economy, New Governance Approaches? Fostering Creativity and Knowledge in the Barcelona Metropolitan Region», Creative Industries Journal, 3 (1-2): pp. 29-46.

Pareja-Eastaway, M. i J. M. Piqué (2010): «La identitat del territori en l'economia del coneixement», Paradigmes, 5, pp. 183-193.

Pareja-Eastaway, M. (2011): «Barcelona creativa: nuevos actores, nuevos programas», Finisterra. Revista de Geografía Portuguesa. Finisterra, XLV, 90, 2010: pp. 133-152.

RHodes, R. A. W. (1997): Understanding Governance: Policy Networks, Governance, Reflexivity and Accountability, Open University Press, 
Maidenhead, GB, Philadelphia, Us, pp. 252 (Public Policy \& Management).

Sassen, S. (1991): The Global City: New York, London, Tokyo, Princeton University Press, Princeton.

Scott, A. J. (2008): Social Economy of the Metropolis. Cognitive-Cultural Capitalism and the Global Resurgence of Cities, Oxford University Press, Oxford.

Thompson, S. (2000): Creative Economy Raport. 2008. The challenge of Assessing the Creative Economy: Towards Informed Policy-Malking, United Nations, New York. 